\title{
AUTOMATED DEVELOPMENT OF CONSTRUCTION SCHEDULES USING ONSITE DATA ACQUISITION
}

*Magdy Ibrahim ${ }^{1}$, Chantale Germain ${ }^{2}$, Michel Guevremont ${ }^{2}$, Martin Forcier $^{2}$, Osama Moselhi $^{1}$

${ }^{1}$ Concordia University

1515 St. Catherine W, Montreal

Quebec, Canada H3G 2 W1

(*Corresponding author: $\underline{m \text { omari@encs.concordia.ca) }}$

${ }^{2}$ Hydro Quebec,

855 Sainte-Catherine East, Montreal

Quebec, Canada, H2L 4 P5 


\title{
AUTOMATED DEVELOPMENT OF CONSTRUCTION SCHEDULES USING ONSITE DATA ACQUISITION
}

\begin{abstract}
Detailed as-built project schedules are necessary to close out construction projects, benchmarking, forecasting, dispute resolution, and improving cost estimates of future projects. Manual procedures for developments of as-built documentation is time consuming, involves numerous interfaces and human interventions. This paper presents computational framework that encompasses automated site data acquisition and generates schedule updates utilizing commercially available project scheduling software. The work is carried out collaboratively with a Hydro Quebec team. The site data is captured employing mobile computing using iPad® type computers and Wi-Fi. The information is directly compiled in a centralized database server. The synchronization tool is a bi-directional application and is used on servers to communicate with $\mathrm{iPad} \AA$ computers deployed onsite. The captured data is stored in Microsoft SQL $®$ relation database that consists of 63 entities. Computer software application has been developed in Microsoft Visual Basic ${ }^{\circledR}$ (vb.net) environment for extracting the collected site data, linking the database to the as planned schedule, and generating the actual, also known as as-built schedule. The development can be utilized in automated progress reporting, evaluating future bids, generating master schedules and a wide range of efficient EVM applications.
\end{abstract}

\section{KEYWORDS}

Automated data collection, Mobile computing, As-built schedule.

\section{INTRODUCTION}

Construction managers need to keep track of design and construction changes and as-built information in order to control and monitor construction progress. The as-built project information represents how construction was actually performed. In construction projects, most initial data comes from the project job site. On-site engineers acquire data and bring it back to the office to help project managers in decision making. This information is re-entered into various isolated systems such as scheduling systems (Wang et al., 2007).

Traditionally schedule updates, including the generation of as-built schedules, are performed manually. Schedule updates require information such as actual start and finish dates of activities, actual work quantities, actual resources, any delays, change orders, weather, and other factors that affected project completion date. This information is developed through the daily recording of construction site data. The analysis of copious amounts of daily site data recording often requires considerable time and effort. Automation of data capturing, processing and analysis is paramount to ensure timely and accurate analyses, maintain data consistency, reduce human manipulations and minimize user intervention.

Quebec's largest utility owner implemented a site data acquisition system to collect data from construction sites. The system starts with inspectors who are collecting the data directly from the worksite to record manpower, equipment, and their respective activities and locations. This information is stored directly into a centralized database at the end of the day. This information can easily be accessed by database request from any site user, administrator, estimator, planner or corporate personnel. This real site data is used to generate the actual direct cost of the work performed (Guevremont \& Germain, 2012). This 
paper presents a computational framework that encompasses the developed site data acquisition system and automatically generates schedule updates utilizing commercially available project scheduling software.

\section{LITERATURE REVIEW}

Most construction project employ scheduling methods to monitor and control the progress of work and develop progress reports, which involves the recording of construction achievements for detection of deviations from actual plan and for forecasting project performance. (Sanvido \& Paulson, 1992). The as-built project information plays an important role in project planning and control. Engineers responsible for schedule updates and adjustments need access to the as-built information to evaluate productivity and progress. Problems, conflicts, and interferences during construction must be identified so that delays and cost overruns can be avoided. The as-built schedule also provides feedback to designers/engineers to improve their design; construction engineers to improve productivity and contractors would like to keep this information for their future job bidding.

Site data acquisition systems depend on the user intervention for measuring, processing and analyzing data and to prepare it for presentation and storage. The duty of users becomes laborious if the data acquisition process lasts for a long duration and requires continuous repetition of steps. There are three levels of user intervention, manual process which requires high level of user intervention, semiautomated process which requires medium level of user intervention and fully-automated process which requires no or low level of user intervention. New trends and ideas are continuously evolving in the area of Human Computer Interaction and consequently various data acquisition processes have been introduced based on application requirements and the level of user intervention.

The use of site information for tracking and control of construction projects have been examined by studies utilizing various site data collection technologies that ranges from low-end (paper-based) to high-end (e.g., sensing technologies, etc.). The main driver to improve the traditional paper-based processes is to ease the manual work involved.

A group of tools which requires high level of user intervention has been investigated including multimedia (Abudayyeh, 1997), information and communication technologies such as voice and wireless (Sunkpho \& Garrett, 2000; Tsai et al., 2007; Tsai, 2009; Liao \& Tseng, 2010), hand-held tools (Tserng \& Dzeng, 2005; T.Hegazy et al., 2008), and web-based tools (Cheung et al., 2004; Chassiakos \& Sakellaropoulos, 2008). These research efforts had been mainly focused on the potential use of the tools, but they did not provide an automated solution for the project tracking and control. The use of multimedia for delay analysis (Abudayyeh, 1997) is useful but it is still a manual process, which requires time and effort to collect information and link it to the schedule. Hegazy and Abdel-Monem (2012) presented a simplified and low-cost framework for semi automated as built schedule tracking using e-mails. However the framework allows bidirectional communication for site and office personnel, but it does not allow variable progress-tracking frequency (e.g. daily, weekly, monthly) to be applied.

Recently, several researchers examined emerging high-end semi-automated technologies (e.g., barcoding, RFID sensors, 3D Laser scanning, photogrammetry, GPS) for on-site real-time progress monitoring; tracking labor productivity; and tracking materials and equipment. Barcoding and radio frequency identification (RFID), for example, have been used to track the locations of resources (Song et al., 2006; Gajamani \& Varghese, 2007; Shehab \& Moselhi, 2009; El-Omari \& Moselhi, 2011). Image recognition and 3D laser scanning have been used to track the quantities of work performed on site (Kern, 2002; Trupp et al., 2004; Bosche et al., 2008). Photogrammetry has also been integrated with other tools such as 3D laser scanning (El-Omari \& Moselhi, 2007) to extract 3D data from 2D progress images. 


\section{OVERVIEW OF THE INTEGRATED SYSTEM}

\section{Site Data Acquisition Hardware Description}

The iPad®-type computer shown in Figure 1 is used for onsite data collection. It has a height of $24.28 \mathrm{~cm}$ (9.56 inches), a width of $18.97 \mathrm{~cm}$ (7.47 inches), a depth of $1.34 \mathrm{~cm}(0.5$ inch)and weights 0.68 $\mathrm{Kg}(1.5 \mathrm{lbs})$. The $3 \mathrm{G}$ system with satellite network was not used because of potential security breach. Its multi-touch screen has a resolution of 1024 per 728 pixels and a flash memory of $16 \mathrm{~GB}$. Its processor is a $1 \mathrm{GHz}$ designed by Apple and a 25-watt-hour rechargeable lithium-polymer battery with up to 9 hours of autonomy. Macintosh ${ }^{\circledR}$ operating system is used with the apple development. Thermal cases are used for below freezing temperature. (Guevremont \& Germain, 2012).

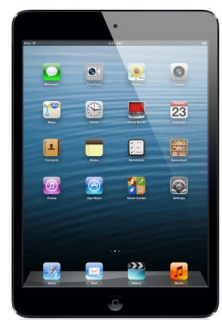

Figure 1 - iPad® type computer used at site

\section{Data Acquisition Implementation and Information Flow}

This system is implemented for tracking of construction activities utilizing the collect site data. Site inspectors collect daily data from the jobsite. The collected data is directly compiled in the database on the ultra-portable computer. This task is performed by the site inspector, validated by the head inspector and then PDF reports are archived on the company's server. At the end of the day, all this data is synchronized to a centralized Microsoft SQL® database housed in the company server. The synchronization tool is a bi-directional application and used on servers to communicate with ultra-portable computers. The layout of the developed system is shown in Figure 2.

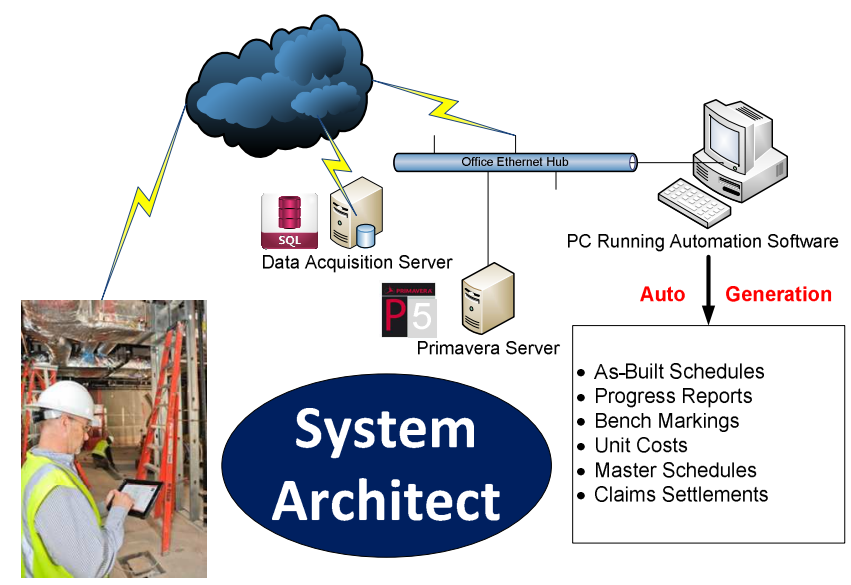

Figure 2 - Electronic System Architecture

The stored data can then easily be accessed from the database by site inspectors, administrator, estimator, planner or corporate personnel. It also provides field estimators and controls department with support for managing potential change orders and claims. Further, it eliminates transcription typos and omissions errors and provides an opportunity for quick benchmarking. 
Each report is classified by a unique number and this allows for easy management of technical modification. Reports are available in PDF format, easy to send and store on the centralized server. Each report generated is specific to a detailed location and activity and can be exported to Microsoft Excel®. Figure 3 shows an example of a detailed report. (Guevremont \& Germain, 2012).

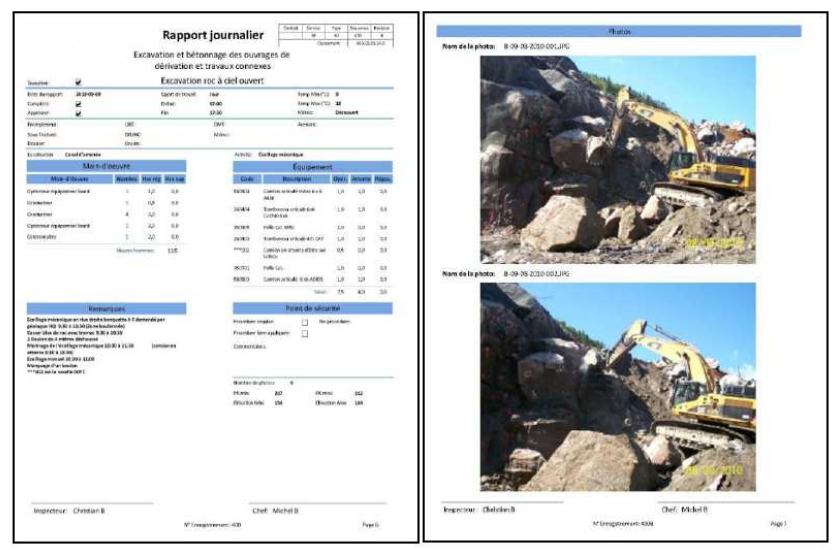

Figure 3 - PDF detailed report (Guevremont \& Germain, 2012)

\section{Linking SQL@ Database to the baseline Schedule}

Primavera $\mathrm{P} 5{ }^{\circledR}$ software is used for scheduling. The baseline schedule incorporates Hydro Quebec's standard work breakdown structure (WBS). The WBS is used for linking the schedule and the database (see Figure 4).

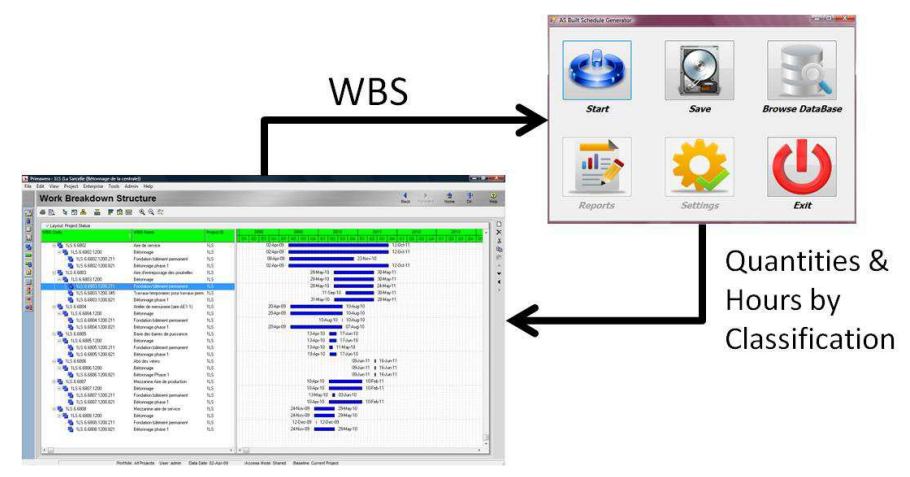

Figure 4 - Link between SQL® Database and Schedule

In order to establish the link between the site data acquisition database and the Primavera ${ }^{\circledR}$ schedule, two new fields were added to the SQL $\circledast$ database. The two new fields were added to the table "tbl_Rapport_Journalier" as shown in Table 1.

Table 1: New Fields for SQL® database

\begin{tabular}{lll}
\hline $\begin{array}{c}\text { Field } \\
\text { Name }\end{array}$ & \multicolumn{1}{c}{ Description } & SQL Type \\
\hline ACT_ID & The activity identification as per the baseline schedule & Varchar(50),Null \\
WBS & The WBS code based on the baseline schedule & Varchar(50),Null \\
\hline
\end{tabular}

The new added fields facilitated the linking and the data exchange between the SQL ${ }^{\circledR}$ database and the Primavera ${ }^{\circledR}$ schedule. The addition of these fields is done automatically by the developed software, using SQL@ queries. 


\section{Database update algorithm}

Each inspection report in the database includes three pieces of information: (1) Type of the report (NoRapport); (2) Location of the work (NoLocalisation); and (3) Task description (NoActivite). These three pieces of information were used to execute a three-phase scanning algorithm to identify each activity and update these activates with the corresponding WBS and activity ID from the baseline schedule as shown in Figure 6. Figure 5 illustrated the two added field in the SQL® database.

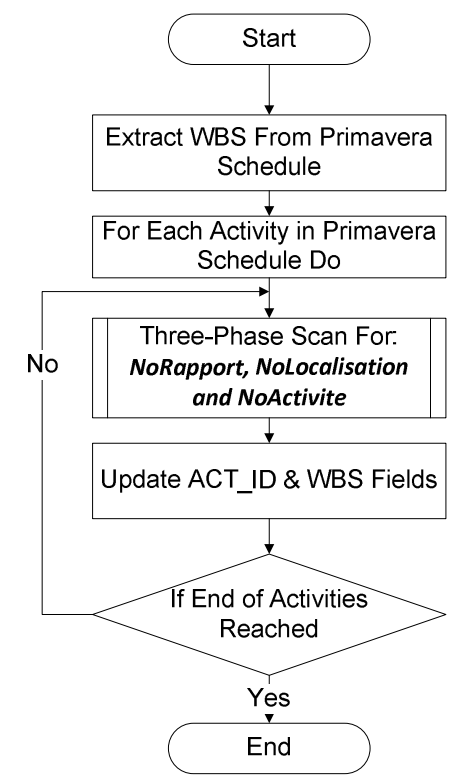

Figure 6: Database Update Algorithm Flowchart

\begin{tabular}{|c|c|c|c|c|c|c|c|}
\hline Complete & Approuve & Transfere & DateApprobation & Approuvelot & Approuvefar & WBS & ACT_ID \\
\hline 1 & 1 & 1 & NULL & 0 & NULL & 1LS.6.6701.1200.821 & $\mathrm{C} 130$ \\
\hline 1 & 1 & 1 & NULLL & 0 & NULL & $1 \mathrm{LS} .6 .6802 .1200 .821$ & 0130 \\
\hline 1 & 1 & 1 & NULL & 0 & NULL & 1LS.6.6802.1200.821 & D130 \\
\hline 1 & 1 & 1 & NULL & 0 & NULL & 1LS.6.6701.1200.821 & $\mathrm{C} 180$ \\
\hline 1 & 1 & 1 & NULL & 0 & NULL & 1LS.6.6000.1200.821 & W130 \\
\hline 1 & 1 & 1 & NULL & 0 & NULL & 1LS.6.6000.1200.821 & W130 \\
\hline 1 & 1 & 1 & NULL & 0 & NULL & 1LS.6.6000.1200.821 & W120 \\
\hline 1 & 1 & 1 & NULL & 0 & NULL & 1LS.6.6802.1200.821 & 0110 \\
\hline 1 & 1 & 1 & NULL & 0 & NULL & 1LS.6.6802.1200.821 & D115 \\
\hline 1 & 1 & 1 & NULL & 0 & NULL & 1LS.6.6802.1200.821 & D130 \\
\hline 1 & 1 & 1 & NULL & 0 & NULL & 1LS.6.6802.1200.821 & D120 \\
\hline 1 & . & + & sแ⿻ & n & sum & 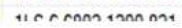 & $n+n n$ \\
\hline
\end{tabular}

Figure 7: Updated SQL® Database

\section{Site Data Extraction}

The Automated schedule generation is based on the actual data stored in the SQL $\AA$ database. After implementing the linking fields in the database as explained in the previous section, the process of extracting the actual data from the database is initiated. The extracted data are: (1) The actual start and finish dates for the activities; (2) The actual assigned resources for each activity; (3) The actual cumulative labor and equipments working hours per activity; and (4) The actual cumulative work quantities per activity. 


\section{Schedule Update and As-built Schedule Generation}

The baseline schedule is updated automatically with the actual site data gathered from the last step. The actual data is based on the inspection reports stored in the SQL ${ }^{\circledR}$ database. The algorithm automatically updates the schedule and generates the as-built schedule as illustrated in Figure 8.

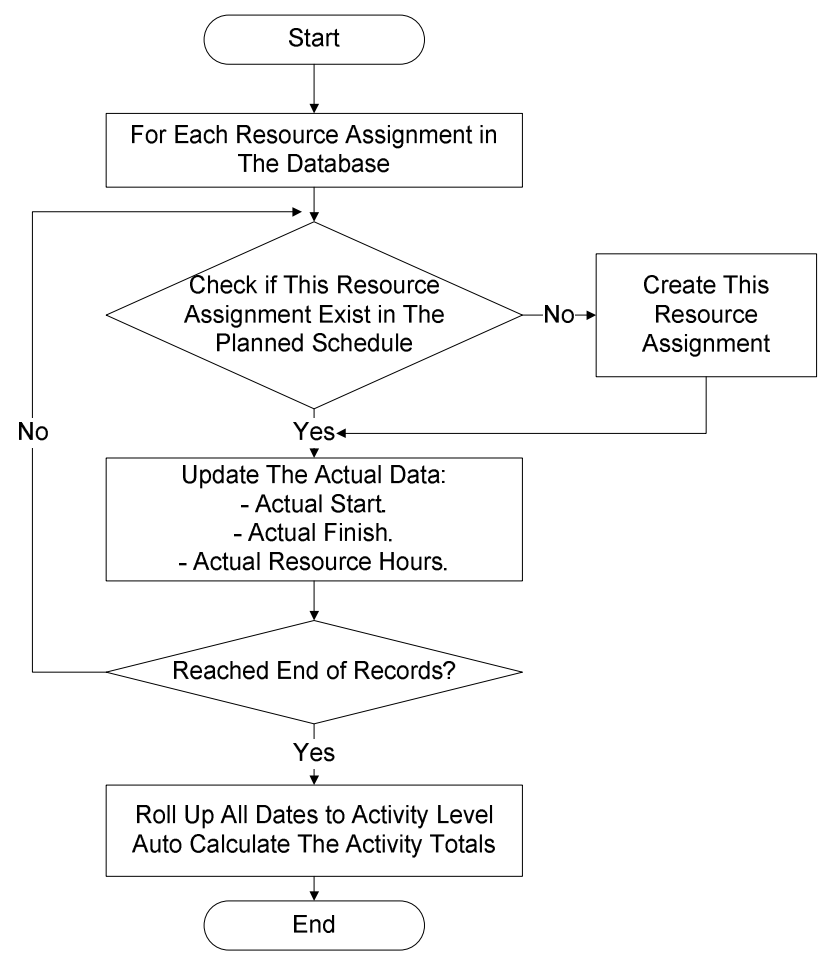

Figure 8: As-built Schedule Generation Algorithm

\section{COMPUTER IMPLEMENTATION}

The software was developed in Microsoft Visual Basic $\circledast$ (.net) environment. The developed tool generated the as-built schedule in Primavera ${ }^{\circledR}$ (.Xer format). The developed system was based on the Primavera ${ }^{\circledR}$ application programming interface (API) to establish the automation of the scheduling update. Its basic components are shown in Figure 9.

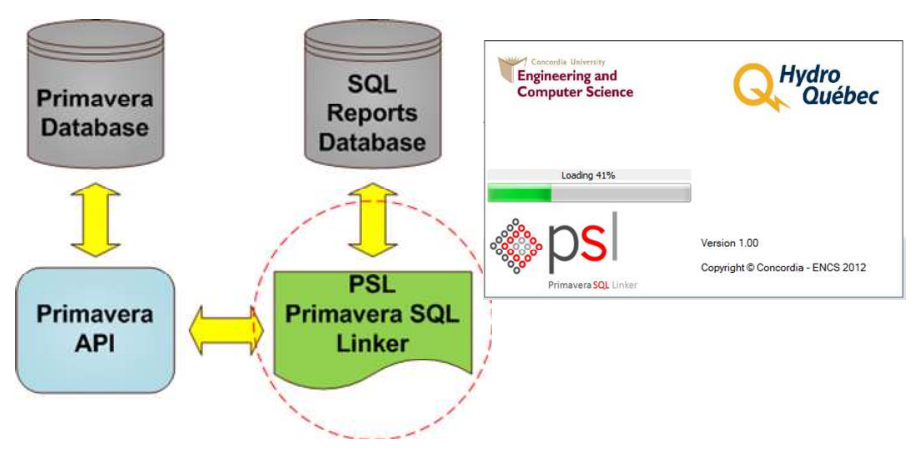

Figure 9 - Software architecture 
The API version P5 is used for the development, but similar approach can be used for P6. The software was validated using an actual data from a hydro project. To realize this, a pilot project data were provided by Hydro Quebec which included the SQLB database (Daily Inspection Reports) and the Primavera (P5) baseline schedule. The database had 15000 reports, the average time for processing and generating the as-built schedule from these reports was 5 minutes on a machine with Intel® core duo CPU @ $2.4 \mathrm{GHz}$ with $4 \mathrm{~GB}$ of Ram and 64 bit operating system. The generated as-built schedule was crosschecked against the actual site data from the database, and the results were accurate.

\section{CONCLUSIONS}

This paper presented a framework to automate as-built schedule generation from daily construction site data, using iPad® type computers. The framework has been developed and implemented for Hydro Quebec's needs. The framework and the computer development were tested on an actual pilot project and the results have been verified for this pilot project. On that specific pilot project, the framework minimized the time and cost associated with onsite data collection, schedule updating and construction status reports generation. Future development with this system could include further management applications using affordable wireless and web enabling. The developed framework provides an example of using communication and information technologies to enhance work collaboration.

\section{REFERENCES}

Abudayyeh, O. Y. (1997). “A multimedia construction delay management system.” Computer-Aided Civil and Infrastructure Engineering, 12 (3), 183-192.

Bosche, F., C. T. Haas, \& P. Murray. (2008). "Performance of automated project progress tracking with 3D data fusion." Annual Conference of the Canadian Society for Civil Engineering 2008" Partnership for Innovation, 349-358.

Chassiakos, A. P., \& S. P. Sakellaropoulos. (2008). "A web-based system for managing construction information.” Advances in Engineering Software, 39 (11), 865-876.

Cheung, S. O., H. C. H. Suen, \& K. K. W. Cheung. (2004). "PPMS: a web-based construction project performance monitoring system." Automation in construction, 13 (3), 361-376.

El-Omari, S., \& O. Moselhi. (2011). "Integrating automated data acquisition technologies for progress reporting of construction projects." Automation in Construction, 20 (6), 699-705.

El-Omari, S., \& O. Moselhi. (2007). "Hybrid methodology for automated collection of data from construction sites." Proceedings of the International Symposium on Automation \& Robotics in Construction and Mining (ISARC)-2007 Kochi, Kerala, India.93-97.

Gajamani, G. K., \& K. Varghese. (2007). "Automated project schedule and inventory monitoring using RFID." Proceedings of the International Symposium on Automation \& Robotics in Construction and Mining (ISARC), 47-53.

Guevremont, M., \& C. Germain. (2012). "Real-Time Data Using iPad® and MR-1® Computers on Construction Projects." Cost Engineering Journal, 54 (5), 40.

Hegazy, T., M. Attalla, L. Hayter, \& S. Penny. (2008). Ultra Mobile Computer System for Accurate and Speedy Inspection of Buildings, CSCE Annual Conference, Québec, Canada, 456-464.

Hegazy, T., \& M. Abdel-Monem. (2012). "Email-based system for documenting construction as-built details." Automation in Construction, 24, 130-137.

Kern, F. (2002). "Precise determination of volume with terestical 3D-laserscanner." Geodesy for Geotechnical and Structural Engineering II, 531-534.

Liao, C. H., \& P. S. Tseng. (2010). "Influential Factors of VoIP Adoption of Top 500 Export-import Enterprises in Taiwan." Contemporary Management Research, 6 (1), 11-28.

Sanvido, V. E., \& B. C. Paulson. (1992). "Site-level construction information system." Journal of construction engineering and management, $118(4), 701-715$.

Shehab, T., O. Moselhi, \& E. Nasr. (2009). "Barcode-assisted system for document management of construction projects." International Journal of Construction Education and Research, 5 (1), 45-60. 
Song, J., C. T. Haas, C. Caldas, E. Ergen, \& B. Akinci. (2006). "Automating the task of tracking the delivery and receipt of fabricated pipe spools in industrial projects." Automation in Construction, 15 (2), 166-177.

Sunkpho, J., J. H. Garrett Jr. \& A. Smailagic. (2000). "Opportunities to use speech recognition for bridge inspection." Proceedings of the ASCE Construction Congress, 184-193.

Trupp, T., L. Soibelman, T. M. A. Hashash, \& L. Y. Liu. (2004). "Novel technologies for construction field data collection.", Proceedings, 10th ICCCBE, Weimar, Germany.

Tsai, M. K. (2009). "Improving communication barriers for on-site information flow: An exploratory study." Advanced Engineering Informatics, 23 (3), 323-331.

Tsai, M. K., J. B. Yang, \& C. Y. Lin. (2007). "Integrating wireless and speech technologies for synchronous on-site data collection." Automation in construction, 16 (3), 378-391.

Tserng, H. P., R. J. Dzeng, Y. C. Lin, \& S. T. Lin. (2005). "Mobile construction supply chain management using PDA and bar codes." Computer-Aided Civil and Infrastructure Engineering, 20 (4), 242264.

Wang, L. C., Y. C. Lin, \& P. H. Lin. (2007). "Dynamic mobile RFID-based supply chain control and management system in construction." Advanced Engineering Informatics, 21 (4), 377-390. 